\title{
EDITORIAL
}

\section{STEPHEN BLACK}

This is a Special Issue of Literacy and Numeracy Studies which, because of its length and the number of articles featured (six), we have made into a combined volume 16(2)/17(1) 2009. We refer to the Issue as showcasing a 'social practice' perspective on adult literacy and numeracy because each article fits within and builds upon a conceptual framework in which various literacies are viewed as social practices. Commonly, this perspective is also described as the 'new literacy studies' or a 'socio-cultural' or 'situated' perspective.

As researchers in this volume indicate (Reder in particular), the social practice perspective has gained considerable recognition in the area of adult literacy and numeracy research, but to date it has had far less impact in the policy and program areas. To briefly illustrate this point, I begin this editorial with a short anecdote. What follows is a verbatim extract from a recent email exchange in which a vocational counsellor in TAFE, the main public vocational education and training provider in Australia, refers a student to the adult basic education (ABE) section of a TAFE college. The counsellor writes:

I would like to refer $\mathrm{S}$ (name of student) to $\mathrm{ABE}$ for assessment and placement in an appropriate literacy class. $\mathrm{S}$ has been enrolled in the Fitness Certificate 3 but is about to withdraw because of her extremely low literacy levels. I have done brief cognitive and literacy assessments and find that while she is within the average range for cognitive potential, she is below the $5^{\text {th }}$ percentile and $1^{\text {st }}$ percentile for her word recognition and spelling respectively. She reports extremely disrupted and unsatisfactory primary and secondary education in her country of birth in Ireland. Could you or your staff contact her ...?

This anecdote does not of course reflect a social practice perspective on literacy; rather, it is the very antithesis, and this is the point to be made. I use this anecdote to highlight why we need and promote an alternative social practice perspective. I would contend that this counsellor's perspective on literacy represents dominant understandings, not only in this counsellor's own professional field, but probably more generally, at least in the field of vocational education and training. That is, literacy is viewed as a singular 
entity which can be measured accurately and presumably generalised across all the domains of one's life, including at work, at home and in the community (i.e. it is 'autonomous' of social context). Further, that there may be an underlying assumption of a relationship with intelligence levels (hence measures of 'cognitive potential'), and that professional experts determine on the basis of their tests which individuals are deemed lacking in literacy skills and refer them to other experts for remedial assistance. One outcome of such a perspective is internalised feelings of personal failure and lack of worth that many individuals experience as the result of being labelled as having low levels of literacy. The student featured in the above anecdote, for example, later left a telephone message with ABE staff cancelling an appointment and saying she thought they would be wasting their time trying to improve her literacy skills.

The articles in this Special Issue of Literacy and Numeracy Studies challenge this dominant perspective and offer instead an alternative perspective which can be seen to be a more productive, democratic and inclusive discourse on the roles of literacy and numeracy in the everyday lives of individuals within communities. These articles were drawn originally from a series of papers for a symposium at the American Education Research Association conference in Chicago, Illinois in April 2007, and revised for publication in this journal. Sondra Cuban at Lancaster University in the UK played a leading role in collating the following articles and liaising with the authors and we thank her for her efforts.

The articles in this Special Issue cover a wide range of areas, some more directly related to adult literacy and numeracy pedagogy than others. This is part of the strength of a social practice perspective, the boundaries between formal and informal education and everyday life contexts are blurred. In place of dominant institutional constructions of literacy, the focus shifts instead to the meanings of literacy practices as viewed by people themselves in a range of different social contexts. Cuban draws out these distinctions in her opening article in which she locates social practice research within a strong socio-political context. In a wide-ranging article, she demonstrates how social practice research stands in contrast to the prevailing 'skills-based' philosophies which underpin adult literacy and numeracy provision in the United Kingdom and the United States, and which currently are seen as the 'elixir' for the knowledge-based economies of neo-liberal political systems. Social practice research offers a wide angle lens through which to view (and critique) these globalising trends through in-depth analyses of the complexities of social life.

Following Cuban, Papen, in an article on health literacy, also presents a social practice view on literacy as a direct challenge to the traditional and dominant ways of viewing literacy. Frequently, health literacy is viewed as an abstract set of skills that can be measured by performance tests in order 
to determine how health literate an individual may be. But such tests ignore the contextual nature of health literacy. Papen explores how individuals navigate their own health care, including how they engage with textuallymediated health care processes. Papen argues essentially that health literacy needs to be situated and focused on practices (and not just skills) and that it is frequently a shared resource, achieved collectively by groups of people, and especially families.

Reder presents a different approach from these authors in his efforts to incorporate practice-based pedagogy and measures in adult basic education programs. Unusually for a social practice researcher, his research methods include quantitative research data. Through statistical modelling based on data from a major longitudinal study of adult learning in the United States, he indicates that participation in basic skills programs impacts on literacy practice measures but not on literacy proficiency measures. And yet, proficiency measures, that is, measures of short term learning gains, dominate the accountability regimes of adult literacy policy and programs in the United States and internationally. Further, his study indicates that engagement in literacy practices over time leads to increases in literacy proficiency, thus strengthening the case for practice-based pedagogy and measures in adult basic education programs.

Barton in his article on adult learners' lives, and Hamilton in her article exploring changing literacy practices through the 'lens of ageing', both selectively draw on findings from their previous qualitative studies to illuminate aspects of a social practice perspective. Barton focuses on the relationships between adult learners' lives and the language, literacy and numeracy learnings in which they are engaged. Employing a range of methods, including observation and in-depth interviews, he explains the aim is to observe people engaging in literacy practices, "within the frame of their lives and sociocultural contexts, and to listen to what they say about these practices and the meanings the practices have in their lives'. His findings indicate the complex range of issues that need to be taken into account in literacy learning, including the skills and competencies people have that are often unrelated to the official curriculum, and background factors such as previous negative schooling experiences, histories of violence and trauma and the range of constraints, emotions and aspirations that affect people's participation in learning.

Hamilton's article documents the subjective experiences of older people, their changing networks and affiliations, and the way they are positioned by their literacy-mediated encounters. As a counter to the survey literature in which ageing is usually associated with declining cognitive functioning, a detailed 'ethnographic eye' presents a more complex picture. As people age their life events and their identities in different social domains change. Retirement, for example, and caring for others, and being cared for 
lead to engagement with new literacy practices which are frequently mediated through the involvement of family members and other social networks of support.

Completing this Special Issue, Cuban's second article explores the lives of 'undocumented' immigrant women in the United States based on an ethnographic study of a small group of Mexican women who work mainly as cleaners in private homes. These women are not easily or even legally accommodated within existing literacy or ESOL programs with their standardised curriculum and regulatory attendance regimes. Instead, they receive assistance from community-based organisations (CBOs) which operate according to a different logic, advocating for the rights of immigrants and organised flexibly to accommodate the women's working lives. Cuban uses the term 'caring literacies' to describe how the women both receive assistance and in turn, as active agents, provide assistance to others within their community networks in their efforts to improve their lives.

These articles provide an important contribution to the growing body of literature on a social practice perspective on adult literacy and numeracy. They provide further evidence of the appropriateness of such a perspective in tackling major social justice issues in so many educational and noneducational contexts. The challenge is to extend these concepts from academic research domains into mainstream thinking in the educational policy and program areas. For example, returning to the anecdote at the beginning of this editorial, when educational or vocational counsellors dispense with their primary focus on standardised literacy and cognitive tests, and instead engage in genuine dialogue with students over how these students view their everyday world and the meanings they attach to the role of literacy practices within it, then we will know we are making some progress. 